\title{
Commentary: Timing for heart transplant after left ventricular assist device implantation--There is no secret recipe!
}

\author{
Michel Carrier, MD, MBA, and Yoan Lamarche, MD, MSC
}

\author{
From the Division of Cardiac Surgery, University of Montreal, Montreal Heart Institute, Montréal, Québec, \\ Canada. \\ Disclosures: Authors have nothing to disclose with regard to commercial support. \\ Received for publication Jan 12, 2019; accepted for publication Jan 13, 2019; available ahead of print April 10, \\ 2019. \\ Address for reprints: Michel Carrier, MD, MBA, Montreal Heart Institute, 5000 E Belanger St, Montréal, Québec, \\ Canada H1T 1C8 (E-mail: michel.carrier@icm-mhi.org). \\ J Thorac Cardiovasc Surg 2019;157:2327 \\ $0022-5223 / \$ 36.00$ \\ Copyright (c) 2019 by The American Association for Thoracic Surgery \\ https://doi.org/10.1016/j.jtcvs.2019.01.043
}

The optimal timing for listing patients for heart transplantation has never been well standardized, especially for patients with left ventricular assist devices (LVADs). In the current issue of the Journal, Brown and colleagues ${ }^{1}$ report their review from the Medicare database of 1186 patients with LVADs who underwent heart transplants between 2009 and 2014. Brown and colleagues ${ }^{1}$ conclude that patients undergoing heart transplants within the first 34 days after LVAD implantation were at greater risk of mortality than were those who underwent transplants after this first month of LVAD support.

Although the study is welcomed to answer the difficult question of the optimal timing for heart transplantation in patients with LVADs, there are various limitations to the database used by Brown and colleagues. ${ }^{1}$ Missing data, lack of information about donor hearts, and unclear reasons for early listing for transplantation are major limitations to the conclusions of Brown and colleagues. ${ }^{1}$ There were 549 patients $(20 \%$ of the total number) excluded from the analysis because of missing data. No reason was given for listing for transplantation of the 28 patients listed within 1 month of LVAD surgery. Furthermore, the mean time between LVAD implantation and heart transplant was $15 \pm 9$ days!

Although information was provided about mechanical complications, bleeding events, pump thrombosis, and infection (long-term LVAD complications), no information was provided about acute organ failure and right ventricular dysfunction (early LVAD complications). We suggest that patients who underwent transplant within 30 days were in 2 groups: those who had an excellent postoperative course and were listed early (may be too early) and those who had severe right ventricular dysfunction with or without organ failure (life-threatening event). The former group could be expected to have reduced transplant risk, and the second group could be at very high risk of perioperative complications. In fact, we suspect that a good number of these patients should have shown life-threatening complications necessitating emergency listing. This is supported by the higher

\section{Reference} 2315-24.e4.

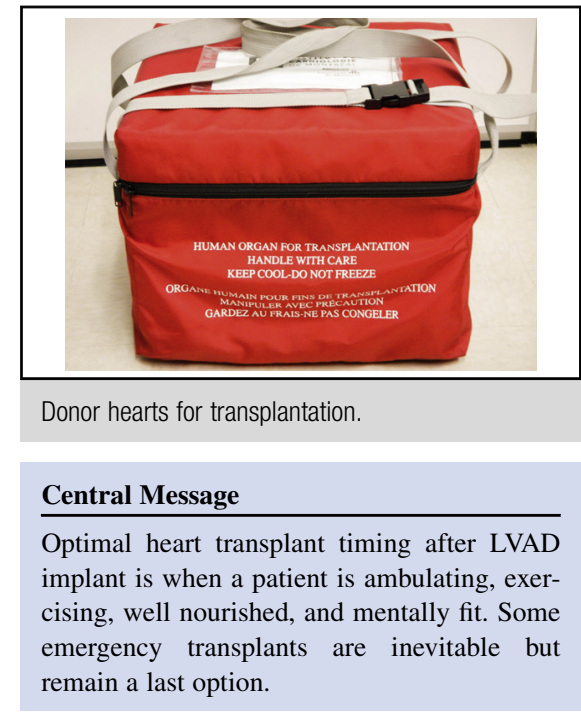

See Article page 2315 .

incidence of posttransplant respiratory and renal failure in the early transplant group. These complications may have been present before the transplant. Unfortunately, the Medicare database fell short in providing answers to those questions, leaving a hypothesis for future work on the subject.

Now, can we still conclude and make some recommendations? The current Canadian and US allocation algorithms for heart transplants give priority to patients supported with extracorporeal membrane oxygenation, to those with short- term devices, and to those with life-threatening complications. The optimal timing to list patients for heart transplant after LVAD implantation should be considered to be when a patient is ambulating, exercising, well nourished, and mentally fit. Emergency transplant early after LVAD implantation in response to life-threatening complications may be inevitable in some cases, but it has been shown to carry a very high risk. The study of Brown and colleagues ${ }^{1}$ adds to this body of literature and encourages transplant teams to consider every option before considering transplant very early after LVAD implantation.

1. Brown CR, Khurshan F, Chen Z, Groeneveld PW, McCarthy F, Acker M, et al Optimal timing for heart transplantation in patients bridged with left ventricular assist devices: is timing the essence? J Thorac Cardiovasc Surg. 2019;157: 